\title{
VIGOR DE SEMENTES DE MILHO ASSOCIADO À MATO-COMPETIÇÃO ${ }^{1}$
}

\author{
MARCOS ALTOMANI NEVES DIAS ${ }^{2}$, VITOR HENRIQUE VAZ MONDO ${ }^{3}$, \\ SILVIO MOURE CICERO ${ }^{4}$
}

\begin{abstract}
RESUMO - O vigor de sementes está relacionado diretamente com a emergência rápida e uniforme de plântulas e crescimento inicial das plantas, fator que pode auxiliar significativamente na habilidade competitiva por recursos como água, luz e nutrientes. Dessa forma, objetivou-se neste trabalho avaliar o efeito do vigor de sementes de milho sobre o crescimento inicial das populações de plantas, produtividade final e competição com plantas daninhas. A pesquisa foi conduzida em área experimental da Universidade de São Paulo, Piracicaba, SP, no ano agrícola de 2007/2008. Foram utilizados quatro lotes de sementes certificadas do milho híbrido DOW8480, com diferentes níveis de vigor, compondo oito tratamentos, com controle e sem controle de plantas daninhas. As análises de campo ocorreram nos estádios fenológicos de 2, 4, 6 e 8 folhas, mensurando-se as plantas quanto altura, diâmetro de colmo e índice de área foliar. Avaliou-se, também, a radiação solar incidente na entrelinha da cultura no estádio fenológico de 4 folhas. No pendoamento, foram realizadas coletas de plantas daninhas presentes nas parcelas, as quais foram avaliadas quanto ao acúmulo de massa de matéria seca e, na colheita, foi avaliada a produtividade de grãos. Os resultados indicaram que vigor das sementes tem efeitos diretos no crescimento inicial da cultura, o que reflete na habilidade competitiva das plantas de milho com plantas daninhas, as quais têm menor crescimento. Além disso, quando em competição maximizada por recursos, o vigor das sementes influencia diretamente na produtividade de grãos.
\end{abstract}

Termos para indexação: potencial fisiológico, produtividade de grãos, Zea mays L., plantas daninhas.

\section{MAIZE SEED VIGOR AND WEED COMPETITION}

\begin{abstract}
Seed vigor is directly related to rapid and uniform seedling emergence and to crop initial development, factor which should have significant effects on the ability of plants to compete for the uptake of resources such as water, light and soil nutrients. It was investigated the effects of maize seed vigor on crop initial growth, yield and weed competition. The experiment was conducted in an experimental area at the University of Sao Paulo, Piracicaba, SP, Brazil during the 2007/2008 growing season and used four lots of maize seed hybrid DOW8480, previously characterized with different vigor levels, grown on plots with and without weed control to give a total of eight treatments. Field analysis were made at the 2, 4, 6 and 8 leaves development stages when plants were evaluated by height, stem diameter and leaf area index. The solar radiation incident on intercrop lines was also measured at the 4 leaf development stage. Weed samples
\end{abstract}

${ }^{1}$ Submetido em 01/10/2009. Aceito para publicação em 06/01/2010.

${ }^{2}$ Graduando em Engenharia Agronômica, USP/ESALQ; bolsista da FAPESP; e-mail: marcosaltomani@yahoo.com.br.

${ }^{3}$ Eng. Agr., Doutorando em Fitotecnia, USP/ESALQ, bolsista CAPES; email: vhvmondo@yahoo.com.br.
${ }^{4}$ Eng. Agr., Dr., Professor Titular, Departamento de Produção Vegetal, USP/ ESALQ; bolsista do CNPq; Caixa Postal 09; CEP 13418-900; Piracicaba, SP; e-mail: smcicero@esalq.usp.br. 
were collected during the maize-tasseling stage and evaluated by dry mass accumulation and maize yield was evaluated at harvest. The results showed that seed vigor is directly related to initial crop growth and that this affects maize plant competitive ability with regard to weeds with inferior growth rates. Furthermore, seed vigor has direct effects on maize yield during maximized competition for the uptake of resources.

Index terms: grain yield, physiological potential, weeds, Zea mays L.

\section{INTRODUÇÃO}

A semente constitui a forma mais eficiente de difusão de novas tecnologias, sendo a ponte de ligação entre o que é desenvolvido pela pesquisa, até alcançar o real beneficiário dessa tecnologia, o produtor rural. Dessa forma, a semente é responsável pelo início da produção agrícola e sua qualidade afeta diretamente todo o desenvolvimento da cultura, desde a emergência de plântulas até o momento da colheita.

O potencial fisiológico de sementes é representado pela germinação e pelo vigor e determina a capacidade da semente em produzir uma plântula normal. $O$ vigor das sementes é representado pelo conjunto de características que confere às sementes potencial para germinar, emergir de forma rápida e uniforme sob ampla diversidade de condições ambientais. Nesse contexto, sementes de baixo vigor podem provocar reduções na porcentagem e na velocidade de emergência de plântulas, no tamanho inicial, na produção de matéria seca, na área foliar e nas taxas de crescimento das plantas (Schuch et al., 1999; Schuch et al., 2000; Machado, 2002; Höfs, 2003, Melo et al., 2006b), podendo afetar o estabelecimento da cultura, o seu desempenho ao longo do ciclo e a produtividade final. A ocorrência de baixo vigor nas sementes pode ser explicada pela necessidade das mesmas da reorganização de seus tecidos e organelas danificadas, pouco antes de dar início ao crescimento do eixo embrionário, retardando a emergência das plântulas (Villiers, 1973).

Rocher et al. (1989), Rood et al. (1990) e Causse et al. (1995) reforçaram a hipótese de que o crescimento inicial é uma característica importante para a capacidade produtiva das plantas de milho, estando relacionado a algumas enzimas chave no processo de fixação e distribuição dos fotoassimilados na planta. O maior crescimento inicial pode incrementar o aproveitamento da radiação solar disponível no início do ciclo da cultura, intensificando o crescimento vegetativo (Almeida et al., 2003).

O aproveitamento da luz é influenciado pela distribuição espacial das plantas na área, pela disposição das folhas na planta e pela extensão da área foliar presente (Fancelli e Dourado Neto, 2000). Segundo os mesmos autores, esse aproveitamento da radiação solar é fundamental no desenvolvimento inicial das plantas, visto que futuramente haverá competição entre as plantas por esse recurso.

$\mathrm{Na}$ agricultura, a competição interespecífica é uma interação negativa, na qual os organismos envolvidos utilizam o mesmo recurso, resultando em prejuízo mútuo ao desenvolvimento (Radosevich et al., 1997). Quando se estuda a competição gerada pela presença das plantas daninhas em áreas cultivadas, essa competição interespecífica passa a afetar às plantas cultivadas e pode ser chamada de matocompetição. Skóra-Neto (2003), estudando a competição entre a cultura do milho e as plantas daninhas, verificou que estas apresentaram maior população no período de quinze dias após a emergência da cultura, com 670 planta. $\mathrm{m}^{-2}$, sendo que a média de todo o ciclo foi de 491 plantas. $m^{-2}$. Este decréscimo ocorreu, segundo o autor, devido à competição intra e interespecífica gerada pelo crescimento das plantas de milho.

As plantas daninhas, assim como todas as outras, exigem água, nutrientes e luz para sobreviver, havendo diferenças entre espécies vegetais quanto à importância relativa da competição acima da superfície do solo (Bianchi et al., 2006). Este tipo de competição induz mudanças morfológicas nas plantas, como redução da espessura foliar e reduções na proporção de matéria seca de raízes em relação à parte aérea (Rajcan e Swanton, 2001). Além disso, sabese que o grau de sombreamento imposto pela cultura causa redução na produção de diásporos pelas plantas daninhas, reduzindo o abastecimento do banco de sementes destas no solo (Radosevich et al., 1997).

O espaçamento nas entrelinhas, também, é fator determinante do grau de sombreamento imposto pela cultura. Em trabalho de Teasdale (1998), a redução das entrelinhas de milho diminuiu o número de plantas e o crescimento de Cyperus esculentus (tiriricão) e Amaranthus retroflexus (caruru gigante) devido ao sombreamento gerado pela cultura.

A competição entre plantas tem sido tema de várias pesquisas. No entanto, a possível influência do vigor das sementes de milho sobre a competição com plantas daninhas é um assunto novo e de grande interesse agronômico. Assim, 
objetivou-se neste trabalho avaliar o efeito do vigor de sementes de milho sobre o crescimento inicial das populações de plantas, competição com plantas daninhas e produtividade final.

\section{MATERIAL E MÉTODOS}

O experimento foi conduzido em área experimental do Departamento de Produção Vegetal, da Escola Superior de Agricultura "Luiz de Queiroz", Universidade de São Paulo (USP/ESALQ/LPV), em Piracicaba, SP, Brasil (latitude: 22'42'30"S; longitude: 47³8'00"W; altitude: $546 \mathrm{~m}$ ). Conduziu-se o experimento na safra 2007/2008, em área de relevo plano a levemente inclinado, solo argiloso de classificação Nitossolo Vermelho eutrófico (Embrapa, 2006) e irrigada por aspersão, via pivô central.

Para a realização do experimento foram utilizados quatro lotes de sementes certificadas de milho (Híbrido DOW8480), cedidas pela empresa Dow AgroSciences, localizada na cidade de Cravinhos, SP, Brasil.

A caracterização inicial dos lotes de sementes foi realizada por meio da determinação do teor de água, utilizando-se o método de estufa a $105 \pm 3{ }^{\circ} \mathrm{C}$ por 24 horas (Brasil, 1992), seguida pela realização de testes fisiológicos, os quais estão descritos a seguir.

Teste de germinação: $\quad$ foi conduzido com quatro repetições de 50 sementes, por lote, em rolos de papel-toalha "Germitest". A quantidade de água adicionada foi equivalente a 2,5 vezes a massa do substrato seco. Os rolos foram acondicionados em germinador e mantidos à temperatura de $25 \pm 1{ }^{\circ} \mathrm{C}$. As contagens, no quarto e sétimo dias após a instalação do teste, seguiram os critérios estabelecidos pelas Regras para Análise de Sementes (Brasil, 1992), contabilizando-se a porcentagem de plântulas normais.

Teste de frio com terra: foi utilizado o teste de frio com terra, em bandejas de plástico $(0,34 \times 0,23 \times 0,07$ $\mathrm{m})$, com mistura de terra e areia na proporção 1:2. Foram semeadas 200 sementes por lote, sendo, em cada bandeja, distribuídas duas repetições de 50 sementes sobre um quilograma do substrato e, em seguida, foram cobertas com mais um quilograma do mesmo substrato. A disponibilidade de água do substrato foi ajustada para $70 \%$ da sua capacidade de retenção. Para reduzir a evaporação, as bandejas foram protegidas com sacos plásticos transparentes e, em seguida, colocadas em câmara fria a $10{ }^{\circ} \mathrm{C}$ por sete dias. Após esse período, as bandejas foram transferidas para germinador a 25 $\pm 1{ }^{\circ} \mathrm{C}$, com iluminação contínua. A avaliação foi realizada após cinco dias, contabilizando-se a porcentagem de plântulas emersas.

Teste de condutividade elétrica: foi conduzido conforme procedimento adotado por Mondo e Cicero (2005), sendo utilizadas quatro repetições de 50 sementes, as quais foram previamente pesadas, colocadas para embeber em um recipiente contendo $75 \mathrm{~mL}$ de água deionizada e mantidas em germinador à temperatura de $25 \pm 1{ }^{\circ} \mathrm{C}$, por 24 horas. Após esse período, foram feitas leituras de condutividade elétrica da solução em aparelho Digimed CD-20 e os resultados expressos em $\mu \mathrm{mho} . \mathrm{cm}^{-1} \cdot \mathrm{g}^{-1}$, obtendo-se a condutividade média por lote.

Teste de envelhecimento acelerado: foi conduzido conforme procedimento adotado por Mondo e Cicero (2005). Foram colocadas quatro repetições de 50 sementes sobre tela de alumínio, distribuídas em uma única camada, em caixas plásticas transparentes $(0,11 \times 0,11 \times 0,03 \mathrm{~m})$ contendo no fundo $40 \mathrm{~mL}$ de água destilada. As caixas plásticas transparentes foram tampadas e mantidas em incubadora do tipo BOD, regulada a $42{ }^{\circ} \mathrm{C}$, durante 96 horas. Após esse período de envelhecimento, as sementes foram submetidas ao teste de germinação, conforme prescrição das Regras de Análise de Sementes (Brasil, 1992), com uma única avaliação aos quatro dias, computando-se a porcentagem de plântulas normais.

Teste de emergência e de velocidade de emergência de plântulas em campo: foi conduzido em área experimental do USP/ESALQ/LPV, com oito repetições de 50 sementes por lote, distribuídas em sulcos de $2,5 \mathrm{~m}$ de comprimento, espaçados $0,5 \mathrm{~m}$ entre linhas e com profundidade de 0,03 $\mathrm{m}$, baseado em metodologia descrita por Fessel et al. (2000). A avaliação foi realizada diariamente, computando-se as plantas emersas, para o cálculo do índice de velocidade de emergência, empregando-se a fórmula proposta por Maguire (1962) e para o cálculo da porcentagem total de plântulas emersas após a estabilização da emergência, que ocorreu no terceiro dia para os lotes 1,2 e 3 e no quinto dia para o lote 4.

Os tratamentos em campo foram constituídos pela semeadura de quatro lotes de sementes com diferentes níveis de vigor em duas condições diferentes, com e sem controle de plantas daninhas, constituindo, dessa forma, oito tratamentos. Utilizou-se, para tanto, dentro de cada condição, delineamento experimental em blocos causalizados com quatro repetições. As parcelas de campo foram compostas de quatro linhas de seis metros de comprimento, espaçadas em $0,7 \mathrm{~m}$, sendo as duas linhas externas e $0,5 \mathrm{~m}$ nas extremidades das linhas destinadas como bordaduras.

A semeadura foi efetuada com semeadoras manuais com limitador de profundidade, sendo semeadas três sementes por cova, espaçadas em $0,2 \mathrm{~m}$ na linha de semeadura. Após quinze dias do início da emergência das plântulas realizou-se um desbaste manual, resultando em população final de 71.429 
plantas.ha ${ }^{-1}$. Para o desenvolvimento do experimento foram realizados procedimentos de adubação, controle de plantas daninhas nos tratamentos que o requeria e controle de pragas, de forma a favorecer o desenvolvimento adequado da cultura.

Para as avaliações em campo, os estádios fenológicos da cultura foram acompanhados de acordo com o procedimento citado por Fancelli e Dourado Neto (2000), tendo como referência o estádio fenológico do lote de maior vigor e com controle de plantas daninhas, com o intuito de identificar corretamente os momentos das avaliações. Dessa forma, foram realizadas avaliações de altura de planta, diâmetro de colmo e índice de área foliar quando as plantas apresentavam 2, 4, 6 e 8 folhas, para análise do crescimento inicial das plantas de milho.

A altura das plantas foi determinada por meio da mensuração do comprimento desde o nível do solo até o ápice da planta, com o limbo foliar distendido, baseando-se em metodologia descrita por Melo et al. (2006a), juntamente com a determinação do diâmetro de colmo, que foi mensurado no colo da planta, com o auxílio de um paquímetro. O índice de área foliar foi calculado pela razão entre a área foliar total de uma planta e a área de solo por ela ocupada, que é a multiplicação do espaçamento entre plantas na linha de semeadura e o espaçamento entre linhas de semeadura. Para tanto, área foliar total foi estimada pela soma da área foliar de cada folha completamente aberta, calculada aplicando-se a equação a seguir, onde $\mathrm{C}$ e $\mathrm{L}$ representam, respectivamente, comprimento e largura média, em metros, de cada folha (Montgomery, 1911).

$$
A F=0,75(C \cdot L)
$$

A intensidade de luz solar foi mensurada nas entrelinhas, utilizando-se tubos solarímetros (TS-UM-3, Eijkelkamp) conectados a um data-logger (Delta-T Devices). Os tubos foram instalados quando as plantas estavam no estádio de quatro folhas completamente distendidas. As leituras foram realizadas de quinze em quinze minutos e depois gerada uma média dos valores obtidos durante sete dias de avaliação.

A avaliação das plantas daninhas foi realizada no estádio fenológico de pendoamento do milho, apenas nos blocos em que não houve controle destas. Para isso foi utilizado um quadrado de madeira com dimensões de $0,5 \times 0,5$ $\mathrm{m}$, segundo metodologia similar utilizada por Meschede et al. (2004), posicionado três vezes, aleatoriamente, na entrelinha central de cada parcela, excluindo-se os espaços destinados à bordadura. As plantas daninhas presentes na área avaliada foram cortadas rente ao solo e colocadas em sacos de papel e, em seguida, colocadas em estufa a $65^{\circ} \mathrm{C}$, até atingir massa constante. Na seqüência utilizou-se uma balança analítica, com sensibilidade de $0,01 \mathrm{~g}$, para a determinação do acúmulo de massa de matéria seca das plantas.

A produtividade de grãos foi determinada pela massa de grãos produzida por parcela, determinada em balança com sensibilidade de $0,1 \mathrm{~g}$, corrigida para o teor de água de $13 \%$. $\mathrm{O}$ teor de água dos grãos colhidos por parcela foi determinado pelo mesmo procedimento adotado para caracterização do lote de sementes, pelo método da estufa a $105 \pm 3{ }^{\circ} \mathrm{C}$ por vinte e quatro horas.

Para a análise estatística da caracterização inicial dos lotes e variáveis de crescimento de plantas, aplicou-se teste F para a análise da variância e, na ocorrência de efeitos significativos, as médias foram comparadas pelo teste de Tukey, com 5\% de significância. Os dados de massa de matéria seca de plantas daninhas e produtividade de grãos foram analisados de forma gráfica com o calculo das médias e respectivos erros padrão. Os dados percentuais foram previamente transformados em arcsen $\sqrt{\frac{x}{100}}$.

\section{RESULTADOS E DISCUSSÃO}

Por meio da caracterização inicial dos lotes de sementes (Tabela 1) pode-se observar a igualdade em termos de porcentagem de germinação entre os lotes e, com a análise conjunta dos resultados dos testes de vigor, diferenças claras de vigor de sementes, definindose o lote 1 como mais vigoroso, lotes 2 e 3 com nível de vigor intermediário e lote 4 como o menos vigoroso.

Os resultados relativos ao crescimento inicial das plantas das populações estão apresentados nas Tabelas 2 , para as parcelas com controle de plantas daninhas, e 3, para as parcelas sem controle de plantas daninhas. De maneira geral, em ambas as áreas, tanto com controle como sem controle de plantas daninhas e, em diferentes momentos de avaliação, houve maior crescimento das populações de plantas originadas do lote mais vigoroso, nesse caso o lote 1 , enquanto o lote 4 , o menos vigoroso, foi o de pior desempenho. Por outro lado, o lote 2 classificado como de vigor intermediário, apresentou nas referidas avaliações, desempenho semelhante ao do lote 1. Ao contrário, o lote 3 também classificado como de vigor intermediário, apresentou desempenho semelhante ao lote 4. Com a análise desses resultados foi possível evidenciar a influência direta do vigor das sementes no crescimento inicial de plantas de milho. Resultados semelhantes têm sido divulgados na comunidade científica, em trabalhos com arroz (Höfs et al., 2004; Melo et al., 2006b; Mielerzski et al., 2008), aveia preta (Schuch et al., 2000) e soja (Vanzolini e Carvalho, 2002; Kolchinski et al., 2005; Kolchinski et al., 2006; Schuch et al., 2009). 
TABELA 1. Caracterização inicial dos lotes de sementes. Teor de água (TA, \%); germinação (G, \%); teste de frio (TF, \%), envelhecimento acelerado (EA, \%); emergência de plântulas em campo (EC, \%); índice de velocidade de emergência (IVE); condutividade elétrica (CE, $\left.\mu \mathrm{mho.cm}{ }^{-1} \cdot \mathrm{g}^{-1}\right)$.

\begin{tabular}{cccccccc}
\hline Lote & TA & G & TF & EA & EC & IVE & CE \\
\hline 1 & 8,6 & $99 \mathrm{a}^{*}$ & $97 \mathrm{a}$ & $91 \mathrm{a}$ & $98 \mathrm{a}$ & $16,0 \mathrm{a}$ & $17,82 \mathrm{a}$ \\
2 & 8,7 & $96 \mathrm{a}$ & $46 \mathrm{~b}$ & $63 \mathrm{~b}$ & $93 \mathrm{a}$ & $14,7 \mathrm{a}$ & $20,97 \mathrm{~b}$ \\
3 & 9,3 & $98 \mathrm{a}$ & $46 \mathrm{~b}$ & $75 \mathrm{~b}$ & $96 \mathrm{a}$ & $14,8 \mathrm{a}$ & $23,77 \mathrm{c}$ \\
4 & 9,7 & $95 \mathrm{a}$ & $2 \mathrm{c}$ & $5 \mathrm{c}$ & $67 \mathrm{~b}$ & $9,0 \mathrm{~b}$ & $27,75 \mathrm{~d}$ \\
\hline $\mathrm{CV}(\%)$ & & 5,6 & 14,3 & 16,7 & 6,6 & 6,8 & 5,8 \\
\hline
\end{tabular}

*Médias seguidas por letras iguais na coluna não diferem entre si pelo teste de Tukey (5\%). CV: coeficiente de variação.

TABELA 2. Variáveis de crescimento de plantas em populações de plantas de milho originadas de lotes de sementes com diferentes níveis de vigor em área com controle de plantas daninhas. Altura de plantas (AP, m); diâmetro de colmo (DC, mm); índice de área foliar (IAF).

\begin{tabular}{|c|c|c|c|c|c|c|c|c|c|c|c|c|}
\hline \multirow{2}{*}{ Lote } & \multicolumn{4}{|c|}{ AP } & \multicolumn{4}{|c|}{ DC } & \multicolumn{4}{|c|}{ IAF } \\
\hline & $2 \mathrm{~F}^{*}$ & $4 \mathrm{~F}$ & $6 \mathrm{~F}$ & $8 \mathrm{~F}$ & $2 \mathrm{~F}$ & $4 \mathrm{~F}$ & $6 \mathrm{~F}$ & $8 \mathrm{~F}$ & $2 \mathrm{~F}$ & $4 \mathrm{~F}$ & $6 \mathrm{~F}$ & $8 \mathrm{~F}$ \\
\hline Lote 1 & $0,30 \mathrm{a}^{* *}$ & $0,56 \mathrm{a}$ & $0,77 \mathrm{a}$ & $1,18 \mathrm{a}$ & $7,3 \mathrm{a}$ & $13,6 a b$ & $17,5 b$ & $23,4^{\mathrm{ns}}$ & $0,038 \mathrm{a}$ & $0,215 \mathrm{a}$ & $0,670^{\mathrm{ns}}$ & $1,200 \mathrm{a}$ \\
\hline Lote 2 & $0,28 \mathrm{ab}$ & $0,57 \mathrm{a}$ & $0,78 \mathrm{a}$ & $1,11 \mathrm{ab}$ & $7,0 \mathrm{a}$ & $13,9 \mathrm{a}$ & $17,4 \mathrm{a}$ & 23,6 & $0,035 \mathrm{ab}$ & $0,215 \mathrm{a}$ & 0,623 & $1,140 \mathrm{ab}$ \\
\hline Lote 3 & $0,21 b c$ & $0,42 b$ & $0,71 \mathrm{ab}$ & $0,99 \mathrm{~b}$ & $4,6 b$ & $9,9 \mathrm{c}$ & $15,6 \mathrm{ab}$ & 22,2 & $0,033 b c$ & $0,148 b$ & 0,528 & $0,990 \mathrm{~b}$ \\
\hline Lote 4 & $0,19 \mathrm{c}$ & $0,41 b$ & $0,67 \mathrm{~b}$ & $0,92 b$ & $4,1 b$ & $10,9 b c$ & $14,1 \mathrm{~b}$ & 22,1 & $0,028 \mathrm{~d}$ & $0,138 b$ & 0,470 & $0,983 b$ \\
\hline $\mathrm{CV}(\%)$ & 17,4 & 11,7 & 5,0 & 8,9 & 14,4 & 11,0 & 6,5 & 9,3 & 20,3 & 15,9 & 18,3 & 7,4 \\
\hline
\end{tabular}

* Estádio fenológico de 2, 4, 6 ou 8 folhas. ** Médias seguidas de mesma letra na coluna não diferem entre si pelo teste de Tukey (5\%). ${ }^{\text {ns }}$ Não significativo pelo teste $\mathrm{F}$, com $5 \%$ de significância. CV: coeficiente de variação.

TABELA 3. Variáveis de crescimento de plantas em populações de plantas de milho originadas de lotes de sementes com diferentes níveis de vigor em áreas sem controle de plantas daninhas. Altura de plantas (AP; m); diâmetro de colmo (DC; mm); índice de área foliar (IAF).

\begin{tabular}{|c|c|c|c|c|c|c|c|c|c|c|c|c|}
\hline \multirow{2}{*}{ Lote } & \multicolumn{4}{|c|}{ AP } & \multicolumn{4}{|c|}{ DC } & \multicolumn{4}{|c|}{ IAF } \\
\hline & $2 \mathrm{~F}^{*}$ & $4 \mathrm{~F}$ & $6 \mathrm{~F}$ & $8 \mathrm{~F}$ & $2 \mathrm{~F}$ & $4 \mathrm{~F}$ & $6 \mathrm{~F}$ & $8 \mathrm{~F}$ & $2 \mathrm{~F}$ & $4 \mathrm{~F}$ & $6 \mathrm{~F}$ & $8 \mathrm{~F}$ \\
\hline Lote 1 & $0,29 a^{* *}$ & $0,55 \mathrm{a}$ & $0,74 \mathrm{ab}$ & $1,03 \mathrm{a}$ & $6,9 a$ & $15,7 \mathrm{a}$ & $22,1 \mathrm{a}$ & $22,9^{\mathrm{ns}}$ & $0,038 \mathrm{a}$ & $0,200 \mathrm{a}$ & $0,595 \mathrm{a}$ & $1,125 \mathrm{a}$ \\
\hline Lote 2 & $0,26 \mathrm{a}$ & $0,53 \mathrm{ab}$ & $0,81 \mathrm{a}$ & $1,07 \mathrm{a}$ & $6,3 \mathrm{a}$ & $14,9 \mathrm{a}$ & $22,2 \mathrm{a}$ & 22,5 & $0,038 \mathrm{a}$ & $0,178 \mathrm{a}$ & $0,575 \mathrm{a}$ & $1,135 \mathrm{a}$ \\
\hline Lote 3 & $0,25 \mathrm{a}$ & $0,44 b$ & $0,64 a b$ & $0,95 \mathrm{ab}$ & $5,6 \mathrm{ab}$ & $11,4 b$ & $17,0 \mathrm{~b}$ & 21,9 & $0,030 \mathrm{a}$ & $0,165 \mathrm{a}$ & $0,468 \mathrm{ab}$ & $1,045 \mathrm{ab}$ \\
\hline Lote 4 & $0,16 \mathrm{~b}$ & $0,32 \mathrm{c}$ & $0,54 \mathrm{~b}$ & $0,78 b$ & $4,1 b$ & $8,0 \mathrm{c}$ & $14,4 b$ & 21,7 & $0,018 b$ & $0,103 b$ & $0,368 \mathrm{~b}$ & $0,860 \mathrm{~b}$ \\
\hline $\mathrm{CV}(\%)$ & 8,5 & 8,9 & 15,9 & 11,6 & 13,1 & 11,5 & 10,4 & 8,2 & 13,6 & 16,2 & 13,5 & 11,0 \\
\hline
\end{tabular}

* Estádio fenológico de 2, 4, 6 ou 8 folhas. ${ }^{* *}$ Médias seguidas de mesma letra na coluna não diferem entre si pelo teste de Tukey (5\%). ${ }^{\text {ns }}$ Não significativo pelo teste $\mathrm{F}$, com $5 \%$ de significância. CV: coeficiente de variação. 
Dessa forma, com o maior crescimento inicial das plantas, esperava-se relação direta com a incidência de radiação solar na entrelinha da cultura, sendo que quanto maior o crescimento inicial da população, menor a incidência de radiação solar. Assim, os dados de radiação solar incidente nas entrelinhas da cultura (Figura 1) indicaram maiores valores de radiação nas entrelinhas das populações de plantas originadas do lote de sementes menos vigoroso (Lote 4), quanto comparados ao lote mais vigoroso (Lote 1), indicando que o crescimento mais rápido das plantas originadas de sementes de alto vigor, proporcionou a cobertura mais eficiente da entrelinha e a menor disponibilidade de luz. Segundo Balbinot Junior e Fleck (2005), alterações nas relações de competição por água, luz e nutrientes entre as plantas de milho e plantas daninhas, em favor da cultura, podem ser alcançadas por práticas de manejo, como a seleção de genótipos que apresentem determinadas características morfofisiológicas, como elevada estatura e rápido crescimento inicial de plantas. Essas considerações vão ao encontro dos efeitos do vigor de sementes sobre o crescimento inicial de plantas de milho aqui encontrados, fator o qual é fundamental na competição da cultura com plantas daninhas.

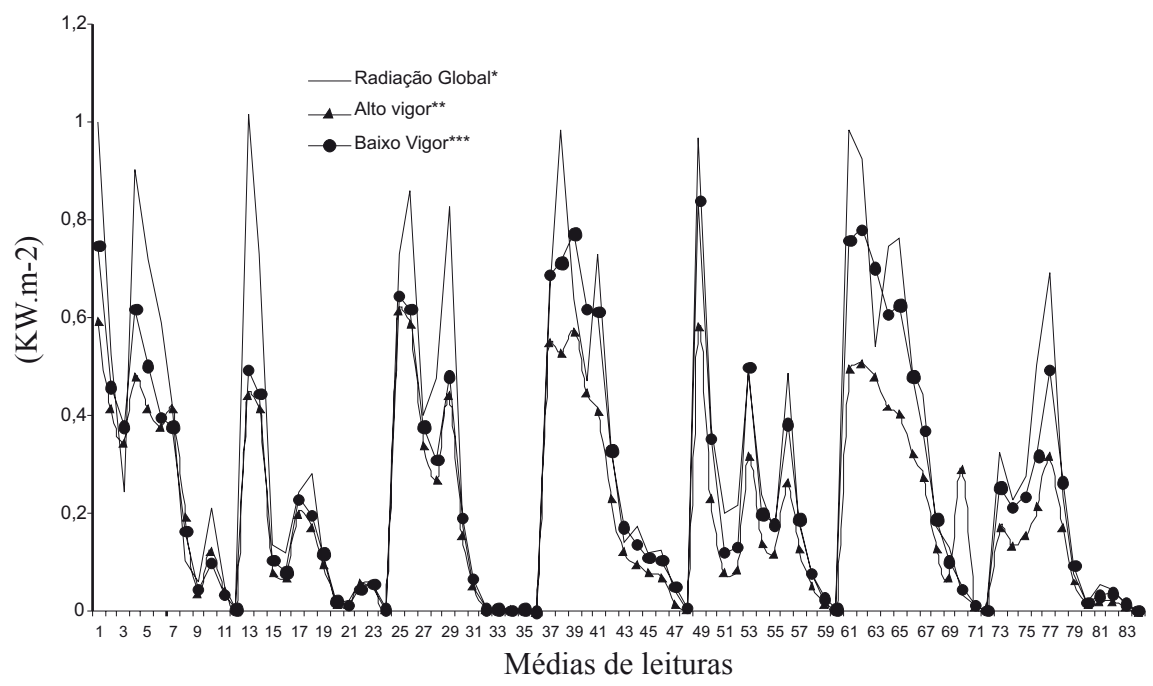

*Radiação solar total, obtida através de dados da estação meteorológica da USP/ESALQ.** Radiação incidente nas entrelinhas do tratamento com lote de sementes com maior nível de vigor (1) e controle de plantas daninhas.*** Radiação incidente nas entrelinhas do tratamento com lote de sementes com menor nível de vigor de sementes e controle de plantas daninhas.

\section{FIGURA 1. Radiação solar incidente nas entrelinhas das populações de plantas de milho originadas de lotes de sementes com diferentes níveis de vigor.}

Nesse sentido, a análise relativa à massa de matéria seca de plantas daninhas nas parcelas onde as mesmas não foram controladas (Figura 2) evidenciou os resultados previamente encontrados. Na Figura 2 pôde-se observar o maior crescimento de plantas daninhas nas parcelas com populações de plantas originadas de sementes de lotes menos vigorosos, podendo-se observar ainda de forma crescente o acúmulo de massa de matéria seca de plantas daninhas a partir das parcelas de lotes mais vigorosos para as de lotes menos vigorosos. Com a análise de todos os resultados foi possível inferir que o efeito do vigor sobre o crescimento inicial de plantas de milho, realmente, ofereceu maior capacidade competitiva à cultura, perante as plantas daninhas.

Com relação à produtividade de grãos (Figura 3), não foram observadas diferenças entre as populações originadas de lotes de sementes diferentes quanto ao nível de vigor nas parcelas onde houve controle de plantas daninhas, resultados que corroboram com os encontrados por Almeida et al. (2003), onde o maior crescimento inicial de plantas de milho não foi traduzido na produtividade final de grãos. No entanto, Merotto Junior et al. (1999) identificaram que a desuniformidade de emergência de plântulas 
de milho reduziu a produtividade de grãos, fator que pode ser encontrado com a utilização de lotes de baixo vigor. Ainda, quando analisadas as produtividades das parcelas sem controle de plantas daninhas, onde o fator competição por recursos foi maximizado, o efeito do vigor encontrado inicialmente no ciclo da cultura continuou até a colheita, sendo que os lotes de sementes menos vigorosos proporcionaram produtividades inferiores aos mais vigorosos.

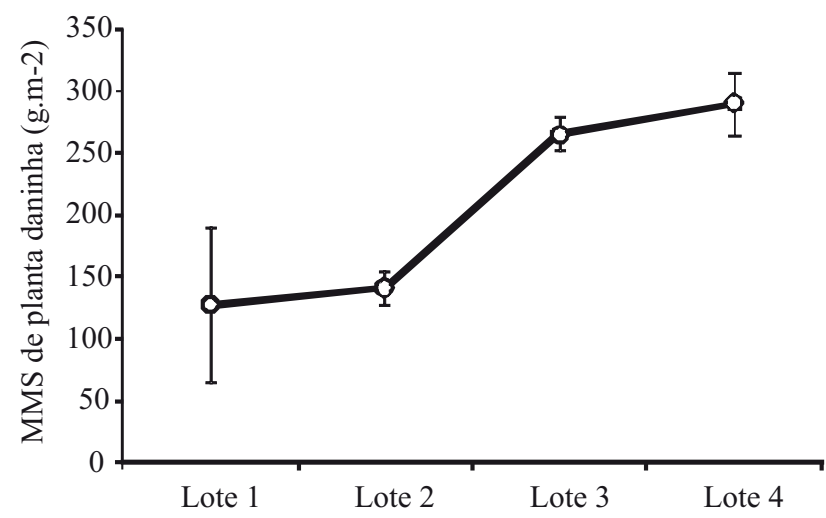

FIGURA 2. Massa de matéria seca de plantas daninhas MMS, em populações de plantas de milho originadas de lotes de sementes com diferentes níveis de vigor.

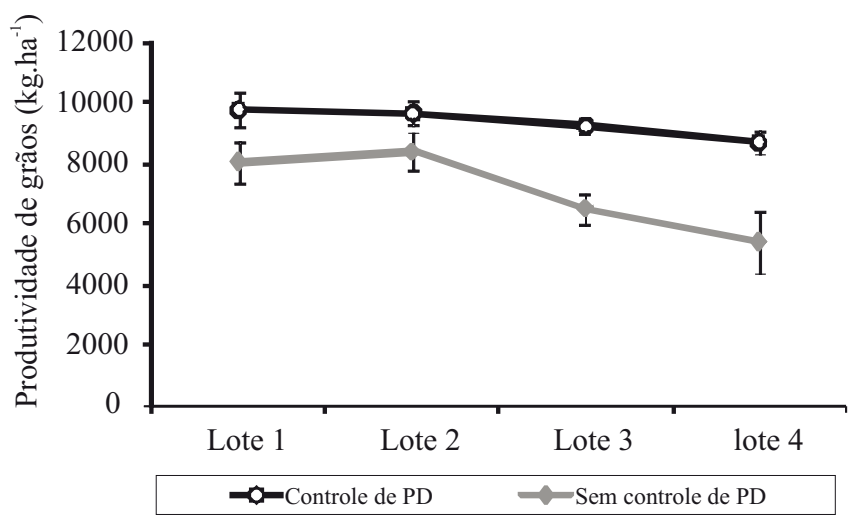

FIGURA 3. Produtividade de grãos $\left(\mathrm{kg} \mathrm{ha}^{-1}\right)$ de populações de plantas de milho originadas de lotes de sementes com diferentes níveis de vigor em áreas com e sem controle de plantas daninhas (PD).
Schuch et al. (2009) verificaram que sementes de soja com alto potencial fisiológico originaram plantas cuja produtividade em grãos foi $25 \%$ superior, quando comparada à produtividade final de plantas oriundas de sementes de baixo potencial fisiológico. No presente trabalho, as diferenças de produtividade foram apenas identificadas quando foi inserido ao sistema o fator competição com plantas daninhas, onde diferenças chegaram em torno de $30 \%$ de acréscimo em produtividade com a utilização de lotes de sementes vigorosos. Esses resultados, para a cultura do milho, provavelmente serão semelhantes em situações onde estresses como temperaturas extremas ou déficit hídrico ocorram durante o ciclo da cultura.

Segundo Tollenaar et al. (1994), a adoção de práticas de manejo que visem posicionar a cultura em situação competitiva vantajosa em relação às plantas daninhas, constitui-se em alternativa viável para reduzir ou até eliminar a utilização de herbicidas e podendo ser inserida como mais uma ferramenta no manejo integrado de controle plantas daninhas.

\section{CONCLUSÕES}

$\mathrm{O}$ vigor das sementes exerce efeitos diretos no crescimento inicial de plantas de milho, o que reflete na habilidade competitiva da cultura com plantas daninhas, as quais têm menor crescimento. Além disso, quando em competição maximizada por recursos, o vigor das sementes influencia diretamente na produtividade de grãos.

\section{REFERÊNCIAS}

ALMEIDA, M.L.; SANGOI, L.; NAVA, I.C.; GALIO, J.; TRENTIN, P.S.; RAMPAZZO, C. Crescimento inicial de milho e sua relação com o rendimento de grãos. Ciência Rural, v.33, n.2, p.189-194, 2003.

BALBINOT JUNIOR, A.A.; FLECK, N.G. Competitividade de dois genótipos de milho com plantas daninhas sob diferentes espaçamentos entre fileiras. Planta Daninha, v.23, n.3, p.415-421, 2005.

BIANCHI, M.A., FLECK, N.G.; DILLENBURG, L.R. Partição da competição por recursos do solo e radiação solar entre cultivares de soja e genótipos concorrentes. Planta Daninha, v.24, n.4, p.629-639, 2006.

BRASIL. Ministério da Agricultura e Reforma Agrária. Secretaria Nacional de Defesa Agropecuária. Departamento Nacional de Defesa Vegetal. Coordenação de Laboratório Vegetal. Regras para análise de sementes. Brasília, DF, 1992. 365p. 
CAUSSE, M.; ROCHER, J.P.; PELLESCHI, S.; BARRIÈRE, Y.; VIENNE, D. de; PRIOUL, J.L. Sucrose phosphate synthase: an enzyme with heterotic activity correlated with maize growth. Crop Science, v.35, n.4, p.995-1011, 1995.

EMPRESABRASILEIRADEPESQUISAAGROPECUÁRIA - EMBRAPA. Sistema Brasileiro de Classificação de Solos. 2. ed. Rio de Janeiro, Embrapa Solos, 2006. 306 p.

FANCELLI, A.L.; DOURADO NETO, D. Produção de milho. Guaíba: Agropecuária, 2000. 360p.

FESSEL， S.A.; RODRIGUES， T.J.D; FAGIOLI, M.; VIERIA, R.D. Temperatura e período de exposição no teste de envelhecimento acelerado em sementes de milho. Revista Brasileira de Sementes, v.22, n.2, p.163-170, 2000.

HÖFS, A. Vigor de sementes de arroz e desempenho da cultura. 2003. 44f. Tese (Doutorado em ciência e tecnologia de sementes) - Universidade Federal de Pelotas, Pelotas, 2003.

HÖFS, A.; SCHUCH, L.O.B.; PESKE, S.T.; BARROS, A.C.S.A. Emergência e crescimento de plântulas de arroz em resposta à qualidade fisiológica de sementes. Revista Brasileira de Sementes, v.26, n.1, p.92-97, 2004.

KOLCHINSKI, E.M.; SCHUCH, L. O.B.; PESKE, S.T. Vigor de sementes e competição intra-específica em soja. Ciência Rural, v.35, n.6, p.1248-1256, 2005.

KOLCHINSKI, E.M.; SCHUCH, L.O.B.; PESKE, S.T. Crescimento de soja em função do vigor das sementes. Revista Brasileira de Agrociência, v.12, n.2, p.163-166, 2006.

MACHADO, R.F. Desempenho de aveia-branca (Avena sativa L.) em função do vigor de sementes e população de plantas. 2002. 46f. Dissertação (Mestrado em ciência e tecnologia de sementes) - Universidade Federal de Pelotas, Pelotas, 2002.

MAGUIRE, J.D. Speed of germination aid in selection and evaluation for seedling emergence and vigor. Crop Science, v.2, n.2, p.176-77, 1962.

MELO, P.C.S. de; ANUNCIAÇÃO FILHO, C.J. da; OLIVEIRA, F.J. de; BASTOS, G.Q.; TABOSA, J.N.; SANTOS, V.F. dos; MELO, M.R.C.S. de. Seleção de genótipos de arroz tolerantes à salinidade durante a fase vegetativa. Ciência Rural, v.36, n.1, p.58-64, 2006a.

MELO, P.T.B.S.; SCHUCH, L.O.B.; ASSIS, F.N. de; CONCENÇO, G. Comportamento individual de plantas originadas de sementes com diferentes níveis de qualidade fisiológica em populações de arroz irrigado. Revista Brasileira de Sementes, v.28, n.2, p.84-94, 2006b.

MEROTTO JÚNIOR, A.; SANGOI, L.; ENDER, M.;
GUIDOLIN, A.F.; HAVERROTH, H.S.A desuniformidade de emergência reduz o rendimento de grãos de milho. Ciência Rural, v.29, n.4, p.595-601, 1999.

MESCHEDE, D.K.; OLIVEIRA-JUNIOR, R.S.; CONSTANTIN, J.; SCAPIM, C.A. Período anterior a interferência de plantas daninhas em soja: estudo de caso com baixo estande e testemunhas duplas. Planta Daninha, v.22, n.2, p.239-246, 2004.

MIELEZRSKI, F.; SCHUCH, L.O.B; PESKE, S.T.; PANOZZO, L.E.; PESKE, F.B.; CARVALHO, R.R. Desempenho individual e de populações de plantas de arroz híbrido em função da qualidade fisiológica das sementes. Revista Brasileira de Sementes, v.30, n.3, p.86-94, 2008.

MONDO, V.H.V.; CICERO, S.M. Análise de imagens na avaliação da qualidade de sementes de milho localizadas em diferentes posições na espiga. Revista Brasileira de Sementes, v.27, p.9-18, 2005.

MONTGOMERY, E.G. Correlation studies in corn. Nebraska Agricultural Experiment Station Annual report, v.24, p.108-159, 1911.

RADOSEVICH, S.R.; HOLT, J.; GHERSA, C. Weed Ecology; implications for management. 2.ed. New York: Willey, 1997. 589p.

RAJCAN, I.; SWANTON,C.J. Understanding maize-weed competition: resource competition, light quality and the whole plant. Field Crops Research, v.71, p.139-150, 2001.

ROCHER, J.P.; PRIOUL, J.L.; LECHARNY, A.; REYSS, A.; JOUSSAUME, M. Genetic variability in carbon fixation, sucrose-P-synthase and ADP glucose pyrophosphorylase in maize plants of differing growth rate. Plant Physiology, v.89, n.2, p.416-420, 1989.

ROOD, S.B.; BUZZELL, R.I.; MAJOR, D.J.; PHARIS, R.P. Gibberellins and heterosis in maize quantitative relationships. Crop Science, v.30, n.1, p.281-286, 1990.

SCHUCH, L.O.B.; NEDEL, J.L.; ASSIS, F.N. de; MAIA, M.S. Crescimento em laboratório de plântulas de aveia-preta (Avena strigosa Schreb.) em função do vigor das sementes. Revista Brasileira de Sementes, v.21, n.1, p.229-234, 1999.

SCHUCH, L.O.B.; NEDEL, J.L.; ASSIS, F.N.de; MAIA, M.S. Vigor de sementes e análise de crescimento de aveia preta. Scientia Agricola, v.57, n.2, p.305-312, 2000.

SCHUCH, L.O.B.; KOLCHINSK, E.M.; FINATTO, J.A. Qualidade fisiológica da semente e desempenho de plantas isoladas em soja. Revista Brasileira de Sementes, v.31, n.1, p.144-149, 2009.

SKÓRA NETO, F. Uso de caracteres fenológicos do milho como indicadores do início da interferência causada 
por plantas daninhas. Planta Daninha, v.21, n.1, p.81-87, 2003.

TEASDALE, J.R. Influence of corn (Zea mays) population and row spacing on corn and velvetleaf (Abutilon theophrasti) yield. Weed Science, v.46, n.4, p.447-453, 1998.

TOLLENAAR, M.; DIBO, A.A.; AGUILARA, A.; WEISE, S.F.; SWANTON, C.J. Effect of crop density on weed interference in maize. Agronomy Journal, v.86, n.4, p.591$595,1994$.
VANZOLINI, S.; CARVALHO, N.M. Efeito do vigor de sementes de soja sobre o seu desempenho em campo. Revista Brasileira de Sementes, v.24, n.1, p.33-41, 2002.

VILLIERS, T.A. Ageing and longevity of seeds in field conditions. In:HEYDECKER, W. (Ed.). Seed Ecology. London: The Pennsylvania State University Press, p.265$288,1973$. 